\title{
ESTADO DA ARTE SOBRE O TEMA DESENVOLVIMENTO MOTOR NA EDUCAÇÃO INFANTIL
}

\author{
Maria Aparecida Carneiro Pedra1 ${ }^{1}$, Lilian Miranda Bastos Pacheco²
}

1.Bolsista PIBIC/FAPESB, Graduanda em Licenciatura em Pedagogia, Universidade Estadual de Feira de Santana, e-mail: mariaaparecida909@g mail.com

2. Orientadora, Departamento de Educação, Universidade Estadual de Feira de Santana, e-mail: lilianmbp01@gmail.com

PALAVRAS-CHAVE: Estado da arte, Psicomotricidade, Educação Infantil

\section{INTRODUÇÃO}

A Educação Infantil é vista como espaço de muitas discussões por ser relativamente nova, com diversos enfoques de pesquisa. O foco aqui escolhido se refere ao desenvolvime nto motor na área da Educação Infantil, no período de dez anos, buscando identificar a temática abordada, o que tem recebido mais visibilidade nas produções acadêmicas, sobre esta área de conhecimento de 2004 a 2013.A pesquisa conhecida como estado da arte, que é de caráter bibliográfico, tem como objetivo elencar e analisar a produção acadêmica em determinada área de conhecimento, período, suporte textual e tema específicos, com o intuito de verificar os aspectos e o modo com que temas característicos estão sendo abordados, apontando sistematizações, lacunas ou novos caminhos para pesquisas. O objetivo geral desta pesquisa é investigar, analisar e catalogar os artigos, publicados em periódicos científicos, acerca do tema "psicomotricidade", na área da Educação Infantil, entre os anos de 2004 e 2013.

O estudo do tipo "estado da arte" ou "estado do conhecimento" se justifica a partir da necessidade de sistematizações e a atualização da produção científica, de suas características e lacunas, além da socialização desse conhecimento produzido através das pesquisas. A partir da análise das investigações com este referencial metodológico é possível ver uma multiplicidade de temas, suporte textual e períodos, sendo tratados. Existem diferentes enfoques analisados nos estudos do tipo estado da arte na Educação Infantil. A presente pesquisa pretende abordar o tema da psicomotricidade. Estudos, sobre este tema não foram encontrados nos periódicos examinados.

\section{METODOLOGIA}

Especificamente falando, os objetivos abrangem identificar e registrar os artigos científicos sobre psicomotricidade acerca da Educação Infantil publicados nos periódicos de excelência, segundo o QUALIS/CAPES; Analisar os artigos sobre à temática específica neste campo do conhecimento; E por fim divulgar as produções decorrentes da pesquisa em eventos científicos. O método de pesquisa estado da arte investiga um gênero textual específico. Nesta investigação o corpus considerado são artigos de pesquisa publicados em periódicos científicos de excelência porque é avaliado pela QUALIS-CAPES. Periódicos classificados como Internacionais na área de Educação, pela QUALIS-CAPES. São os seis periódicos: Caderno de pesquisa - FCC, Educação e Pesquisa - Revista da Faculdade de Educação da USP, Educação e Realidade - UFRGS, Educação e Sociedade -CEDES, Revista Brasileira de Educação ANPED, e Investigações em Ensino de Ciências - UFRGS.Em um segundo momento pesquisou-se na Base de Dados Virtualdo Scielo. As consultas às bases foram feitas com o objetivo de selecionar os artigos científicos na área de conhecimento da Educação infantil e, a partir deste banco de dados, posteriormente, foram selecionados os que tratavam do desenvolvimento psicomotor para a Educação infantil. 
Para o desenvolvimento da etapa de identificação dos artigos que tratassem do desenvolvimento psicomotor na Educação Infantil nos periódicos e período citados, foram usados sete descritores, segundo previu o projeto de pesquisa o qual gerou esta pesquisa: creche, pré-escola, Educação Infantil, zero a cinco anos, criança, infância, associados ao descritor tema desta pesquisa: psicomotricidade. Essas palavras-chaves foram identificadas a partir do título, resumo, e palavras-chaves de cada artigo presente nos periódicos.

Nenhum artigo sobre desenvolvimento motor foi encontrado nos periódicos investigados. Uma outra fonte então foi consultada, sendo 13 artigos encontrados a partir de um único descritor desenvolvimento motor na Base de Dados Virtual Scielo. Eles foram analisados segundo três critérios: data de publicação, característica dos autores, e temática abordada.

\section{RESULTADOS}

Sobre a temática específica deste PLANO DE TRABALHO, nenhum artigo foi encontrado no período de 2004 a 2013, em periódicos classificados pelo QUALIS - CAPES como Internacional, na área de Educação Infantil sobre desenvolvimento psicomotor. Esta é uma lacuna, um silenciamento dos estudos. Este é um assunto muito importante para a formação do professor, psicólogo, profissionais da área do desporto e áreas afins.

A partir deste resultado, por reconhecer a importância da temática, decidimos fazer alguns ajustes metodológicos, no sentido de contemplar outro universo de corpus. Passamos então a consultar os artigos científicos sobre desenvolvimento psicomotor, na Base de Dados Virtual Scielo. Para tanto utilizou-se os descritores Habilidade Motora e Psicomotricidade. Nesta nova pesquisa não utilizamos mais área de conhecimento da Educação Infantil como descritor, mas apenas a temática. Sendo assim todo universo temporal da base de dados (1997hoje) e os periódicos listados foram contemplados na busca. No que tange a Habilidade Motora foram encontrados nove artigos, e sobre a Psicomotricidade foram localizados quatro artigos. Assim se totalizou treze artigos sobre Desenvolvimento Motor. É possível perceber que existem artigos relacionados a temática geral sobre Educação Infantil, mas não se referem à temática do desenvolvimento psicomotor.

Com um recorte temporal de treze anos consecutivos, no quadro a seguir apresentamos de forma mais sucinta o número de artigos publicados por ano. Dos treze artigos, sete foram publicados nos anos mais recentes de 2013 e 2014. De 1997 a 2010 apenas quatro artigos foram publicados sobre a temática. Esta temática é antiga, dentre os estudos, mas observamos uma lacuna temporal. Volta-se a observar interesse pelo tema mais recentemente entre os anos de 2013 e 2014.

\begin{tabular}{|c|c|c|c|c|c|c|c|}
\hline \multicolumn{7}{|c|}{ TABELA 1: Quantidade de Artigos por Ano de Publicação } \\
\hline ANO de Publicação & $\mathbf{1 9 9 7}$ & $\mathbf{1 9 9 8}$ & $\mathbf{1 9 9 9}$ & $\mathbf{2 0 0 0}$ & $\mathbf{2 0 0 1}$ & $\mathbf{2 0 0 2}$ & $\mathbf{2 0 0 3}$ \\
\hline Quantidade de Artigos & 0 & 0 & 0 & 0 & 0 & 1 & 1 \\
\hline ANO de Publicação & $\mathbf{2 0 0 4}$ & $\mathbf{2 0 0 5}$ & $\mathbf{2 0 0 6}$ & $\mathbf{2 0 0 7}$ & $\mathbf{2 0 0 8}$ & $\mathbf{2 0 0 9}$ & $\mathbf{2 0 1 0}$ \\
\hline Quantidade de Artigos & 0 & 0 & 1 & 0 & 1 & 0 & 0 \\
\hline ANO de Publicação & $\mathbf{2 0 1 1}$ & $\mathbf{2 0 1 2}$ & $\mathbf{2 0 1 3}$ & $\mathbf{2 0 1 4}$ & & & \\
\hline Quantidade de Artigos & 2 & 0 & 4 & 3 & & & \\
\hline Total de Artigos & \multicolumn{7}{|c|}{} \\
\hline
\end{tabular}

Fonte: própria, dados do mapeamento.

Como é possível ver na Tabela 1, os artigos localizados concentram-se entre os anos de 2002 a 2014, treze artigos foram publicados. Percebe-se que nos anos de 2002, 2003, 2006 e 2008 foram publicados por ano apenas um artigo respectivamente. A partir de 2011 houve um incremento encontra-se uma maior quantidade, sendo dois nesse ano, e nos dois últimos anos 
de investigação deste trabalho concentram-se a maior parte dos artigos, 7 dos treze. Enquanto que não fora encontrada, desde 1997 até 2010, nenhuma publicação que se referisse ao desenvolvimento psicomotor na área da Educação Infantil.

No que tange a temática, três artigos possuem temática semelhante no que se refere à Aprendizagem Motora. Tani, et ali, 2011; Corrêa, et ali, 2013; e Naves, et ali, 2014 retratam a maneira como a aprendizagem motora influencia na Educação Infantil. Esses estudos acadêmicos enfocam sobre as maneiras como as habilidades motoras são aprendidas e quais fatores podem influenciar neste processo. Outros cinco artigos possuem temática semelhante no que tange a habilidade motora, são os de Souza, et ali, 2006; Turtelli e Tavares, 2008; Silva, et ali, 2013; Andrean, et ali, 2013; Schmitt, e Pereira, 2014 mostrando a relação entre a habilidade Motora e a psicomotricidade; Fernandes, et ali, 2014 abordaram sobre Dificuldades de Aprendizagem; Campos, et ali, 2013 falaram sobre relação da prematuridade com o desenvolvimento motor; Silva, et ali, 2011 relataram a respeito do programa de intervenções motoras; Carvalho, 2003 falou sobre a Psicomotricidade Walloniana; e por fim Sodré, 2002 abordou o desenvolvimento da escrita.

\section{CONSIDERAÇÕES FINAIS}

No campo do desenvolvimento motor os artigos mostram a importância da motricid ade ao esporte para ajudar as crianças com relação a sua aprendizagem e na melhora em relação ao movimento do corpo, analisando dessa forma o quanto é importante aprofundar estudos com relação a esta temática no meio acadêmico. As pesquisas apontam para a necessidade de discutir a respeito deste assunto nos cursos das diversas licenciaturas. O trabalho de estímulo e incentivo ao desenvolvimento da coordenação motora do aluno da pré-escola ressalta a relevância do papel do professor e a participação da família no cotidiano escolar. Faz-se necessário entender a função da escola em favorecer o trabalho com atividades específicas, para aperfeiçoar a coordenação do movimento motor dos alunos.

É importante reconhecer que é por meio do trabalho escolar que a Educação Infantil ofertada pode ser de qualidade, garantindo um melhor aprendizado do aluno. Com isso, percebe-se a importância da pesquisa cientifica, que sem dúvida é um dos mais preciosos bens que a humanidade possui, sem ela, não teríamos um pensamento crítico, nem um futuro com melhorias e avanços. Dessa forma é mais que importante zelar por este bem, mostrando o seu lugar, impulsionando e incentivando cada vez mais a formação de estudantes.

\section{REFERENCIAS}

ANDREAN, Paulo César; FAQUIN, Bruno Secco; DASCAL, Juliana Bayeux; OKAZAKI, Victor Hugo Alves. Efeito da direção da transferência interlateral no aprendizado de tarefa de sequência de toques de dedos. Rev. Bras. Ciênc. Esporte, Mar 2013, vol.35, no.1, p.15-26. ISSN 0101-3289

ASSOCIAÇÃO NACIONAL DE PÓS-GRADUAÇÃO E PESQUISA EM EDUCAÇÃO. Disponível em: 〈http//www.anped.org.br/site/RBE〉. Acesso em: 08 jul. 2016

CADERNO DE PESQUISA. Disponível em < http $/ /$ publicacoes.fcc.org.br/ojs/index.php/cp $>$. Acesso em: 08 jul.2016

CAMPOS, Carolina Maria Coelho; SOARES, Marianne Maila Almeida; CATTUZZO, Maria Teresa. $O$ efeito da prematuridade emhabilidades locomotoras e de controle de objetos de crianças de primeira infância. Motriz: rev. educ. fis., Mar 2013, vol.19, no.1, p.22-33. ISSN 1980-6574

CARVALHO, Elda Maria Rodrigues. Contribuições da teoria Walloniana à educação psicomotora. (Monografia de especialização em Psicomotricidade - UNIFOR), 1996.

Tendências da educação psicomotora sob o enfoque

Walloniano. Psicol. cienc. prof., Set 2003, vol.23, no.3, p.84-89. ISSN 1414-9893 
CORRÊA, Umberto Cesar; SILVA, Silvia Letícia da; FERREIRA, Thiago Rogel Santos; COIMBRÃO, Lilian Granato, TANI, Go. Em busca da quantidade "ótima" de prática constante na estrutura constante-variada: um olhar para a validade ecológica e a especificidade da tarefa. Rev. educ. fis. UEM, Jun 2013, vol.24, no.2, p.195-205. ISSN 19833083

EDUC. Pesq. Disponível em: < http://www.educacaoepesquisa.fe.usp.br $>$. Acesso em: 19. jul. 2016

EDUC. Real. Disponível em: <http//www.scielo.br/revistas/ep/pinstruc.htm>. Acesso em: 19. jul.2016.

EDUC. Soc. Disponível em <http://www.cedes.unicamp.br/publicacoes/20>. Acesso em 26 jul.2016

FERNANDES, Cleonice Terezinha; DANTAS, Paulo Moreira Silva; MOURÃOCARVALHAL, Maria Isabel. Desempenho psicomotor de escolares com dificuldades de aprendizagem em cálculos. Rev. Bras. Estud. Pedagog., Abr 2014, vol.95, no.239, p.112-138. ISSN 2176-6681

INFOCAPES. Boletim Informativo da CAPES. Vol.10 - No 2 - Brasilia, CAPES, 2002

INVESTIGAÇÃO em Ensino de Ciências. Disponível em $\langle$ http:/www.cienciamao.usp.br/tudo/indice.php?midia=ienci> Acessoem. 28. Jul 2016.

SANTOS-NAVES, Suziane Peixoto; BENDA, Rodolfo Novellino; JUNQUEIRA, Aline Horta Miguel; ALVES, Gabriel Menezes; VELLOSO, Ana Luíza Perez Pimenta; UGRINOWITSCH, Herbert. Efeito da demonstração distribuída na aprendizagem do saque do voleibol. Rev Bras Educ Fís Esporte, Dez 2014, vol.28, no.4, p.629-639. ISSN 1807-5509

SILVA, Cristiane Bhering Moretzsohn; BENDA, Rodolfo Novellino; FONSECA, Fabiano de Souza; FIALHO, João Vitor Alves Pereira; MENZEL, Hans-Joachim Karl. Mudança no foco de atenção ao longo da prática de uma habilidade motora. Motriz: rev. educ. fis., Jun 2013, vol.19, no.2, p.391-398. ISSN 1980-6574

SILVA, Eva Vilma Alves da; CONTREIRA, Andressa Ribeiro; BELTRAME, Thaís Silva; SPERANDIO, Fabiana Flores. Programa de intervenção motora para escolares com indicativo de transtomo do desenvolvimento da coordenação - TDC. Rev. bras. educ. espec., Abr 2011, vol.17, no.1, p.137-150. ISSN 1413-6538

SCHMITT, Beatriz Dittrich; PEREIRA, Karina. Caracterização das ações motoras de crianças com baixa visão e visão normal durante o brincar: cubos com e sem estímulo luminoso ou alto contraste. Rev. bras. educ. espec., Set 2014, vol.20, no.3, p.435-448. ISSN 1413-6538

SCIELO. Disponível em <http://www.scielo.br/scielo.php?lng=pt>. Acesso em 26 jul.2016 SODRÉ, Liana Gonçalves Pontes. Estudo de crianças na reprodução dos componentes gráficos da escrita. Psicol. Esc. Educ. (Impr.), Jun 2002, vol.6, no.1, p.39-50. ISSN 1413-8557 Souza DE; França FR; Campos TF. Teste de labirinto: instrumento de análise na aquisição de uma habilidade motora. Rev. bras. fisioter., Set 2006, vol.10, no.3, p.355-360. ISSN 14133555

TANI, Go; BRUZI, Alessandro Teodoro; BASTOS, Flávio Henrique; CHIVIACOWSKY, Suzete. O estudo da demonstração em aprendizagem motora: estado da arte, desafios e perspectivas. Rev. bras. cineantropom. Desempenho hum. (Online), Out 2011, vol.13, no.5, p.392-403. ISSN 1980-0037

TURTELLI, Larissa Sato; TAVARES, Maria Consolação Gomes Cunha Fernandes. Movimento humano em uma perspectiva psicossomática: estudos de Judith Kestenberg. Psic.: Teor. e Pesq., Jun. 2008, vol.24, no.2, p.217-224. ISSN 0102-3772 